\title{
Interactive comment on "Seasonal deposition processes and chronology of a varved Holocene lake sediment record from Lake Chatyr Kol (Kyrgyz Republic)" by Julia Kalanke et al.
}

\section{Anonymous Referee \#2}

Received and published: 19 February 2020

Kalanke et al.

The paper entitled "Seasonal deposition processes and chronology of a varved Holocene lake sediment record from Lake Chatyr Kol (Kyrgyz Republic)" from Kalanke et al. presents a very detailed and almost continuous varved record spanning the past $\sim 11,000$ years in a region where high-resolution paleoclimate data is currently lacking. This makes this record very exciting for the overall paleoclimate community. The MS is very well written, and the figures are excellent and easy to understand. Many dating techniques are shown including $\mathrm{Pb}-210$ and $\mathrm{Cs}-137$, radiocarbon and most importantly, varve counting. Hence, this paper is clearly suited for this journal. 
Although I have no major comment on the central topic of this paper (that is suitable for the journal), i.e. the chronology, I am puzzled why there is no $\mu$-XRF data (e.g. Itrax) shown in your study. For example, the authors describe periods of prevailing anoxic bottom water conditions, calcitic materials/diatoms, coarse vs finer sediments, etc. In my opinion, it would be very helpful to show $\mu$-XRF elements (and elemental ratios) to support your visual microscopic analysis. Have you made such analysis (XRF)? If you are to interpret the paleoenvironments from this site in the paper, I think that would be very valuable.

Moderate comments:

1- There is an excellent matching between the varve count with the 2 dated wood samples. However, there is almost 6000 years (first $\sim 360 \mathrm{~cm}$ ) without chronological constraint. Given that many varves are qualified as 'unclear' from $130 \mathrm{~cm}$ to $\sim 270 \mathrm{~cm}$ of the composite depth, perhaps some other dating techniques could be added such as paleomag, OSL, $14 \mathrm{C}$, etc. I would encourage the authors to at least comment on this.

2- Have you used any particular software to count the varves, please provide what you used.

3- The names of the cores and their depth are indicated in Fig.3. However, it is unclear in my opinion which cores were used for the composite. I assume A10, and some part of the A3o, A3u. . In brief how much sediment was used from each core sections?

4- Fig. 1 : Have you obtained several (7) gravity cores that are not in the same location of the composite core?

5- Solar activity: Lines 414-416: Raspopov et al., (2008) use a 100-300 year bandpass filter and find 'great correlation' with solar activity (inferred from 14C) from three locations or so, and with lags (as high as 150 years). One can do the same analysis with white noise and find similar correlation (for example see Turner et al. 2016: Solar 
cycles or random processes?). But more importantly, they filter out (bandpass) the data which make any high correlation not surprising at all. The comparison of the tree-rings and $14 \mathrm{C}$ prod rate (Fig. 1; Raspopov et al., 2008) without filtering is not very convincing either. Finally, they don't use the actual instrumental sunspots data spanning the past $\sim 300$ years to compare with their tree-ring records, which is a little bit curious. To be honest, I don't reject the influence of solar forcing on regional climate, but based on this paper, it does not help your interpretation of the connection between solar forcing and your site.

5b: Lines 414: "which show decadal-to centennial periodicities". The authors refer to Fig. 4 LZ II. This is an image; hard to see any decadal-to centennial periodicities. Can you make spectral analysis of these layers characterizing lithozone II to prove these periodicities? It could be challenging without i.e. $\mu$-XRF data.

6 - In the text the authors use $A D$, please add $A D / B C$ in your plots.

Minor comments :

Lines 37-38 : Why Lake Telmen is varved $\sim 1940-2013$ ? Human influence (N \& P) in the watershed? If so, this is not the case for your site?

Figures 5 and 6 : add error bars on CRS/CIC model

Lines : 164-233-763 : change centimetre to centimeter

Figure 1: should add labelling to isobaths.

Line 301: laminar denudation: please describe this.

Line 461: Why such an increase of precipitation at AD 1150? MCA? However, it seems to last until recent, so occurring in the LIA as well. A change in boundary conditions in the watershed? High-resolution grain-size analysis could shed some light about this.

Turner, T. Edward, et al. "Solar cycles or random processes? Evaluating solar variability in Holocene climate records." Scientific reports 6.1 (2016): 1-15. 
Interactive comment on Geochronology Discuss., https://doi.org/10.5194/gchron-2019-18, 2020.

\section{GChronD}

Interactive comment 